\title{
Modeling of piston ring wear
}

\section{Rodríguez, Ana López; Vølund, Anders; Klit, Peder}

\section{Published in:}

Proceedings of the Institution of Mechanical Engineers, Part J: Journal of Engineering Tribology

Link to article, DOI:

$10.1177 / 1350650120929860$

Publication date:

2021

\section{Document Version}

Peer reviewed version

Link back to DTU Orbit

\section{Citation (APA):}

Rodríguez, A. L., Vølund, A., \& Klit, P. (2021). Modeling of piston ring wear. Proceedings of the Institution of Mechanical Engineers, Part J: Journal of Engineering Tribology, 235(3), 629-638.

https://doi.org/10.1177/1350650120929860

\section{General rights}

Copyright and moral rights for the publications made accessible in the public portal are retained by the authors and/or other copyright owners and it is a condition of accessing publications that users recognise and abide by the legal requirements associated with these rights.

- Users may download and print one copy of any publication from the public portal for the purpose of private study or research.

- You may not further distribute the material or use it for any profit-making activity or commercial gain

- You may freely distribute the URL identifying the publication in the public portal

If you believe that this document breaches copyright please contact us providing details, and we will remove access to the work immediately and investigate your claim 


\title{
Modeling of Piston Ring Wear
}

\author{
Ana López Rodríguez ${ }^{2}$, Anders Vølund ${ }^{2}$ and Peder Klit ${ }^{1}$
}

\begin{abstract}
A theoretical study of piston ring wear in large two stroke engines is presented. Piston rings in combustion engines are manufactured with an initially defined shape of the surface contacting the cylinder liner. Further the ring surface working against the cylinder liner is coated with layers of ceramic materials to accommodate the running-in process. Most rings are delivered with a non-flat shape (parabolic) when delivered from the ring supplier. After running in which is typically many hours of operation $(>1000 \mathrm{~h}$ ) the ceramic layers are worn and the ring geometry is typically changed significantly by surface wear. It is shown in the present study that the geometry of the worn ring depends on the operation scheme of the engine. l.e. both the load pattern and the order in which the loads are applied influences the final shape of the ring surface.
\end{abstract}

\section{Keywords}

Piston Ring; Surface Wear; Combustion Engine; Friction Model; Wear Model.

\section{Introduction}

Component failure in a machinery can provoke the untimely destruction of other pieces, and the entire system may cease to work. Therefore, it is important for designers to predict the behaviour of the components over long time periods. In the case of combustion engines piston rings suffer a large amount of wear and are therefore critical components when wear is considered.

Piston rings are mounted along the piston of internal combustion engines, fitted tightly into grooves with the objective of sealing combustion gases. The rings are separated from the liner by a thin film of lubricant as seen in figure 2. The thickness of the film will depend on the viscosity of the oil, the relative velocity between ring and liner and the pressure drop across the ring. When the film becomes too thin, wear will occur and as a result the geometry of the piston ring and cylinder liner are affected. The rings are essential to maintain the efficiency of the combustion process, prevent excessive oil consumption, lower the frictional power loss and minimize the amount of wear.

Piston rings have an annular shape and the shape of the surface in contact with the cylinder liner depends on the position of the ring. The profile will determine the pressure distribution along the contact and is designed to ensure the correct oil film thickness between the wall and the ring. In this investigation focus is on the top ring. The ring used in this work is assumed to have a parabolic shape, corresponding to a new and unworn ring.

Several loads are acting on the piston ring. These come from pressures in the combustion chamber, pre-loading of the ring, pressure in the oil and friction forces in the sliding contact. At low velocities the friction forces are high, caused by asperity contact of the two surfaces and insufficient oil film thickness. As the velocity increases the friction force

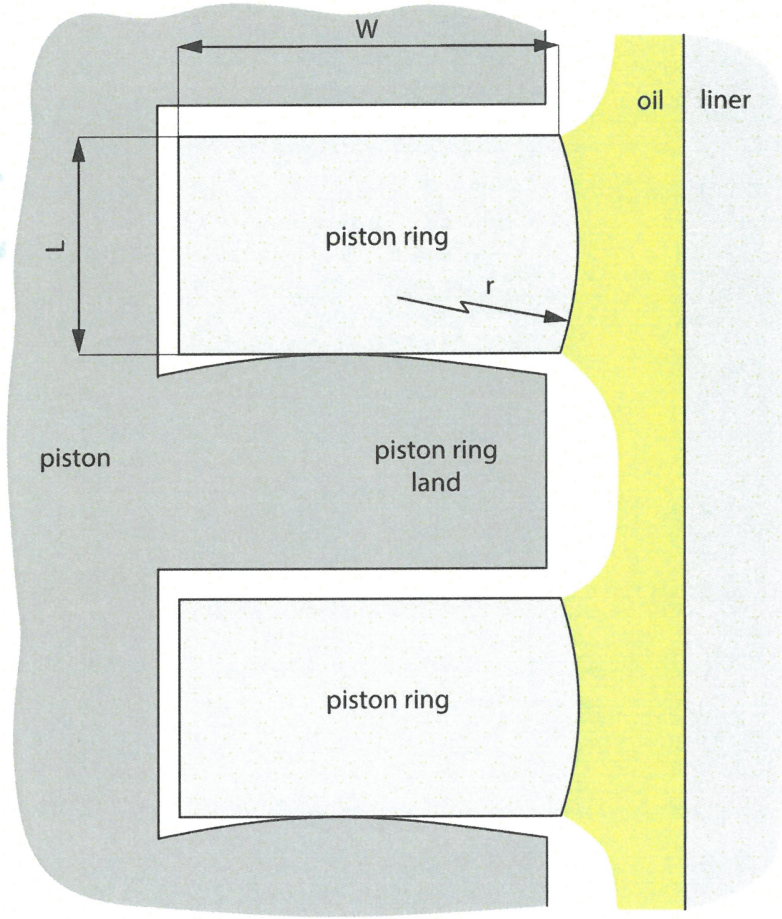

Figure 1. Cross section of two piston rings mounted in their piston ring grooves.

lowers and the contact enters the hydrodynamic lubrication

\footnotetext{
${ }^{1}$ The Technical University of Denmark, DK

${ }^{2}$ MAN Energy Solutions SE, DK
}

\section{Corresponding author:}

Peder Klit, Department of Mechanical Engineering, The Technical University of Denmark

Email: klit@mek.dtu.dk 


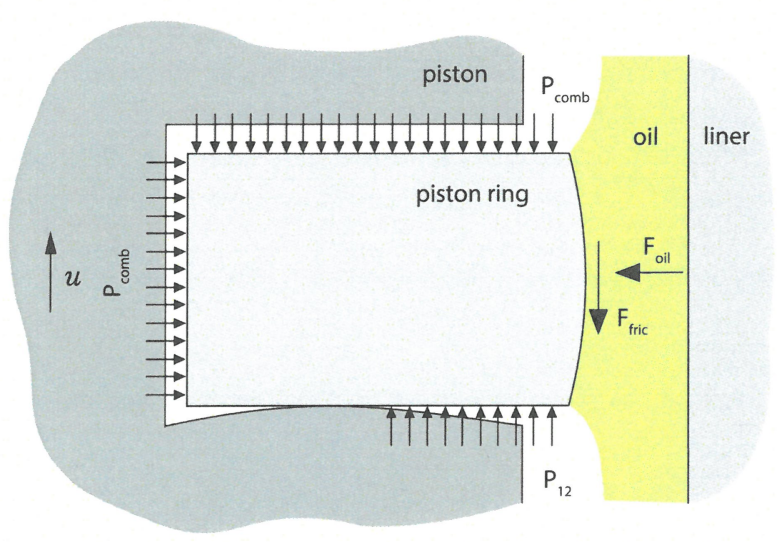

Figure 2. Cross section of a piston ring mounted in the piston groove.

regime, where the two surfaces are fully separated by the oil film. Lack of separation at low velocities leads to wear on both piston rings and cylinder liner.

Wear of piston rings is of great importance. Depending on how the piston ring is worn the pressure distribution between ring and liner changes and affects the tribological condition. Modelling the wear process is challenging and assumptions are required in order to simulate this phenomena, as there are many factors influencing wear, such as the lubricant and the materials of the liner and the ring.

Experiments have been made in order to study the wear process, such as described in ${ }^{1}$. In this paper the piston ring geometry is studied after several hours of operation, varying the amount of lubricant so both starved and fully flooded lubrication conditions are considered. $\mathrm{In}^{2}$ it is studied how the radius of curvature of the ring in axial direction influences minimum film thickness, friction force and wear. It is demonstrated how changes in the ring geometry play an important role for the piston ring operation.

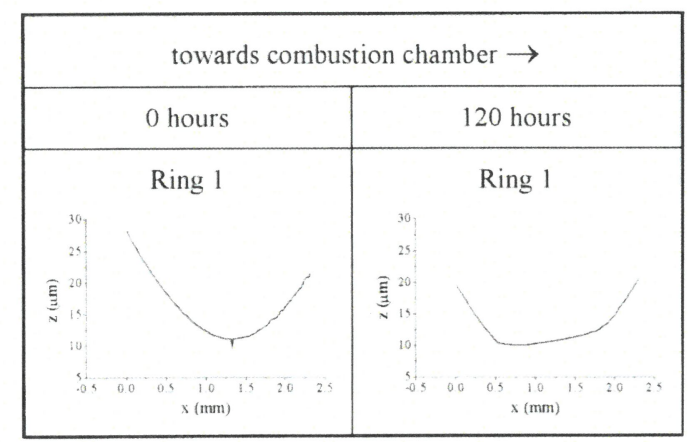

Figure 3. The profile of the running surface of the piston ring. Left: new and unworn ring. Right: ring after $120 \mathrm{~h}^{1}$.

In figure 3 from $^{1}$ it is seen how wear occurs asymmetrically on the surface of the ring. This is due to a series of factors. The ring is twisted by pressure difference across the ring. This pressure difference will vary through the combustion cycle. The twisting of the ring will vary accordingly and will therefore favour a larger amount of wear where the smallest oil film thickness is located. The location of this point depends on the amount of deformation of the liner and twist of the ring. The deformation of the liner surface is a result of the thermal dilatation.
These phenomena are implemented in the numerical model presented. The aim of this model is to predict the shape of piston compression rings during operation.

Wear will take place when the film thickness becomes adequately low. As presented by $\mathrm{Coy}^{3}$, conditions of hydrodynamic lubrication at the mid-stroke region of the piston motion give rise to full film lubrication $(\lambda>5)$ and zero wear, while sliding at lower speed in the vicinity of the dead centres of the piston motion causes mixed lubrication $(\lambda<5)$ and wear.

For low wear rates, the wear can be estimated from changes in the bearing ratio, representing the contact area between ring and liner ${ }^{4}$. For high wear rates, the wear volume can be determined directly from mass loss.

The most intensive wear of the piston ring-liner contact occurs during the running-in where high asperity peaks are worn off by the counter surface ${ }^{5}$. The abrasive wear decreases as the surface irregularities become smaller. This break-in wear is normally a self-stabilising process leading to a decrease in the wear rate of both the piston rings and the cylinder liner ${ }^{67}$.

According to experimental work presented by Henein and co-workers, the wear rate of a cylinder liner is many times higher during the first hour of operation than during the subsequent hours ${ }^{8}$. At steady-state conditions, after runningin, the wear rates of the respective counter bodies is a fraction of the level experienced during the running-in.

One of the first tribologist's who discussed wear on piston rings was ${ }^{9}$, but the first attempt to implement piston ring wear modelling was done by ${ }^{5}$ and ${ }^{1}$.

During the last 20 years numerous papers have been devoted to both experimental and analytical/numerical studies of wear of piston ring-liner contacts.

Papadopoulos et al. ${ }^{10}$ investigated the influence from piston ring coatings and found significant reduction of piston ring wear for coated rings.

Truhana et al. ${ }^{11}$ reported on laboratory test methods to measure the friction and wear characteristics of ring and liner materials in heavy duty engines. Different oils were used to determine the ability of the test methods to detect variations in lubricant performance. In the tests the relative liner wear rate compared to the ring was much higher than encountered in the engine.

Ma et al. ${ }^{12}$ presented a one-dimensional mixed lubrication, wear, and friction model. Wear is computed from the surface asperity contact model. The predicted wear of ring and liner shows good agreement with the measured wear.

Zhang et al. ${ }^{13}$ presented a comprehensive numerical 3 $\mathrm{D}$ wear model for piston ring and cylinder liner. The wear predicted was in good agreement with measured wear on marine diesel engines.

Wear of the piston rings and the cylinder liner is a difficult phenomenon to implement in a calculation model. The required simulation time increases when wear models are included in the simulation software. The wear of the piston ring modifies the ring profile so that the wear phenomenon must be included in a realistic model. 


\section{Nomenclature}

Variables

$a_{0}$ - Vogels eq. param. [Pas]

B - Damping coefficient [ $\left.\mathrm{Ns} / \mathrm{m}^{2}\right]$

$\mathrm{d}$ - Bore diameter [m]

$\mathrm{F}$ - Force [N/m]

$\mathrm{f}$ - Flexibility of ring land $[\mathrm{m} / \mathrm{N}]$

$\mathrm{h}$ - Film thickness [m]

L - Ring width, axial dir. [m]

1 - Shaft length [m]

$\mathrm{O}$ - Origin of coordinate systems

$\mathrm{P}$ - Pressure $[\mathrm{Pa}]$

$\mathrm{r}$ - Radius of curvature [m]

$r_{c}$ - Crank radius [m]

$R_{q}$ - Surface roughness [m]

$\mathrm{T}$ - Temperature $[\mathrm{C}]$

$T_{1,2}$ - Vogels eq. param. [C]

$\mathrm{t}$ - Time [s]

$\mathrm{u}$ - Velocity $[\mathrm{m} / \mathrm{s}]$

$\mathrm{x}$ - Coordinate in $\mathrm{x}$-axis [m]

$\mathrm{y}$ - Coordinate in y-axis [m]

W - Ring width, radial dir. [m]

\section{Greek letters}

$\Delta$ - Difference

$\eta$ - Dynamic viscosity [Pas]

$\theta$ - Crank angle [rad]

$\lambda$-Specific film thickness

$\mu$ - Friction coefficient

$\sigma$ - Composite surface roughness [m]

$\phi$ - Ring twist angle [rad]

$\omega$ - Angular velocity [ $\mathrm{rad} / \mathrm{s}]$

\section{Subscripts}

0 - Minimum film thickness

0 - Global coordinate system

1 - Local coordinate system

12 - Between piston rings

comb - Combustion chamber

dif - Difference

ext - External

fric - Friction

in - Index for minimum film thickness

initial - Initial

$\mathrm{j}$ - Index, iteration

$\mathrm{k}$ - Index, crank angle

liner - Liner

min - Minimum

mod - Modified

$\mathrm{n}$ - Number of points in FDM

oil - Oil

ring - Piston ring

wear - Wear

\section{The Analyzed Case}

In the present study a particular piston ring has been investigated. It is worth noting the physical dimensions of the test case to fully understand the found values.
Table 1. Parameters used for the simulations

\begin{tabular}{|l|l|l|}
\hline Ring face width & $\mathrm{L}[\mathrm{mm}]$ & 9.5 \\
Radius of curvature & $\mathrm{r}[\mathrm{mm}]$ & 1750 \\
Crank radius & $r_{c}[\mathrm{~mm}]$ & 1200 \\
Connecting rod length & $I[\mathrm{~mm}]$ & 2000 \\
Bore diameter & $\mathrm{d}[\mathrm{mm}]$ & 500 \\
Speed & $\mathrm{n}\left[\mathrm{min}^{-1}\right]$ & $78-123$ \\
Engine Load & {$[\%]$} & $25-100$ \\
Lubricant SAE50@40deg C. & {$[\mathrm{Pas}]$} & 0.220 \\
\hline
\end{tabular}

\section{Reynolds Equation}

The full Reynolds Equation, see ${ }^{14}$, can be simplified by introducing the following assumptions:

1. Lubricant density is constant.

2. Lubricant viscosity is constant across film thickness, but may vary in the direction of motion.

3. Axi-symmetric conditions are assumed.

4. Fully flooded conditions are assumed.

$$
\frac{\partial}{\partial x}\left(h^{3} \frac{\partial p}{\partial x}\right)=6 \mu u \frac{\partial h}{\partial x}+12 \eta \frac{\partial h}{\partial t}
$$

The perturbation method suggested by ${ }^{15},{ }^{16}$ and used by ${ }^{17}$ makes it possible to solve Reynolds Equation in the time domain. This method is briefly described below.

By considering a perturbation in the pressure due to the squeeze term $\frac{\partial h}{\partial t}$, we can write:

$$
p=p_{0}+p_{\Delta} \Delta \dot{h}
$$

Substituting in the Reynolds Equation above:

$$
\begin{aligned}
& \frac{\partial}{\partial x}\left(h_{0}^{3} \frac{\partial\left(p_{0}+p_{\Delta} \Delta \dot{h}\right)}{\partial x}\right)= \\
& 6 \mu u \frac{\partial h_{0}}{\partial x}+12 \eta\left(\frac{\partial h_{0}}{\partial t}+\Delta \dot{h}\right)
\end{aligned}
$$

Rearranging we obtain, see ${ }^{17}$ and ${ }^{18}$ :

$$
\begin{gathered}
\frac{\partial}{\partial x}\left(h_{0}^{3} \frac{\partial p_{0}}{\partial x}\right)=6 \mu u \frac{\partial h_{0}}{\partial x}+12 \eta \frac{\partial h}{\partial t} \\
\frac{\partial}{\partial x}\left(h_{0}^{3} \frac{\partial p_{\Delta}}{\partial x}\right)=12 \eta \\
\frac{\partial}{\partial x}\left(h_{0}^{3} \frac{\partial}{\partial x}\right)\left[\begin{array}{c}
p_{0} \\
p_{\Delta}
\end{array}\right]=\left[\begin{array}{c}
6 \mu u \frac{\partial h_{0}}{\partial x}+12 \eta \frac{\partial h}{\partial t} \\
12 \eta
\end{array}\right]
\end{gathered}
$$

If eq. 6 is discretized and solved numerically by FDM or FEM we see that the coefficient matrix on the left hand side of eq. 6 is the same for the two right hand side equations. The equations can thus be solved simultaneously.

\section{Dynamic load from the combustion process}

During the combustion cycle the operating conditions for the piston ring varies. The tangential velocity of the ring along the liner can be found from a simple geometric model seen in figure 4 . 


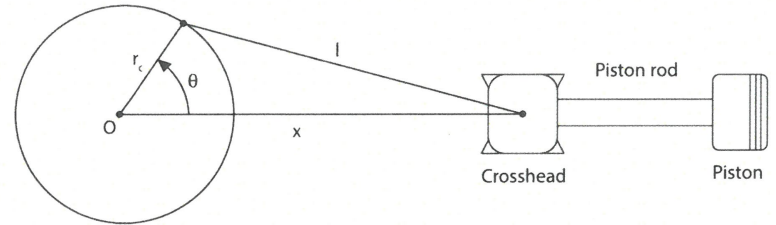

Figure 4. Diagram of the geometry of the engine.

$$
u=-\omega r_{c} \sin (\theta)\left(1+\frac{r_{c} \cos (\theta)}{\sqrt{l^{2}-r_{c}^{2} \sin ^{2} \theta}}\right)
$$

Where $u=\frac{d x}{d t}, \theta$ is the crank angle and $\omega=\frac{d \theta}{d t}$. The ring load stemming from the combustion cycle gas pressure drop across the ring must be specified for the particular problem. This is typically given as pressure values for each crank angle degree.

For each step (typically for each crank angle degree) a balance of forces must be established. An order of magnitude analysis reveals that the inertia terms can be disregarded.

$$
B \Delta \dot{h}=W_{e x t}-F_{o i l}
$$

Where $B$ is the damping coefficient, $W_{\text {ext }}$ the force exerted by the ring and $F_{\text {oil }}$ the force of the oil. The force from the oil is obtained by integrating the pressure distribution, that is the $p_{0}$ obtained from the solution of Reynolds equation in the system from eq. 6 , and the damping coefficient $B$ is found as the integration of $p_{\Delta}$ :

$$
\begin{gathered}
F_{\text {oil }}=\int_{x_{1}}^{x_{n}} p_{0} d x \\
B=\int_{x_{1}}^{x_{n}} p_{\Delta} d x
\end{gathered}
$$

From eq. $8 \Delta \dot{h}$ can be found and used to adjust the squeeze term in the next iterative step

$$
\dot{h}_{j+1}=\dot{h}_{j}+\Delta \dot{h}
$$

With this new squeeze term the pressures $p_{0}$ and $p_{\Delta \dot{h}}$ are calculated again and so are $F_{\text {oil }}$ and $B$ and $\Delta \dot{h}$. These step are repeated until the following criteria is met:

$$
10^{-5}>\left|\frac{W_{e x t, k}-F_{\text {oil }}}{W_{\text {ext }, k}}\right|
$$

Once this condition is fulfilled the next crank angle position can be calculated.

To begin the iterations for the new crank angle the height function is modified. Here, $\Delta t$ is the difference in time between the successive crank angles and the size of $\Delta t$ is chosen to ensure the system remains stable. Therefore the product $\dot{h}_{k} \Delta t$ will be the change in height from one crank angle to the next.

$$
h_{k+1}=h_{k}+\dot{h}_{k} \Delta t
$$

These equations are implemented into a simulation program capable of doing the calculations. The flow chart of the calculation setup can be seen in figure 5 .

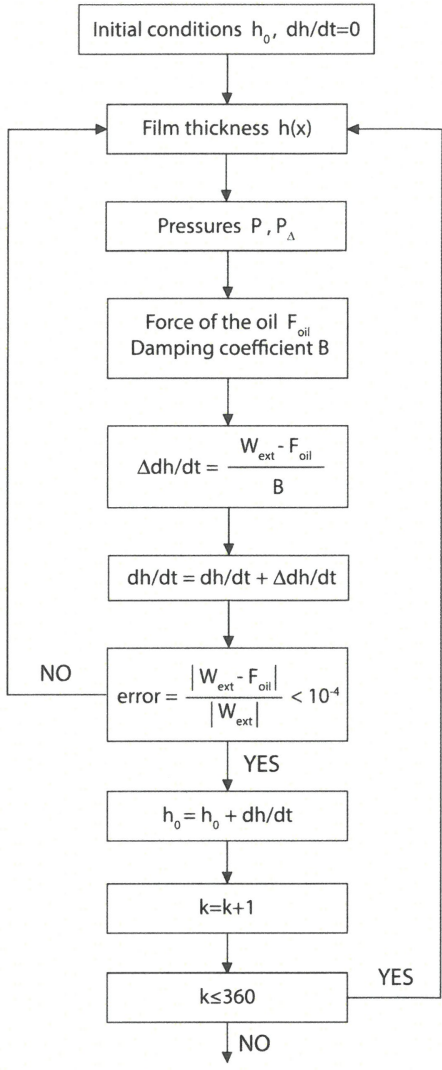

Figure 5. Flow chart of the resolution of the film thickness calculation.

\section{Piston ring wear}

Near the top and bottom dead centers the tangential velocity of the piston ring approaches zero. As a result the film thickness becomes small and asperity contact between the piston ring and liner causes wear.

Wear is a complex process and it is generally difficult to model. In this study a simple wear model is implemented. To introduce wear it is necessary to determine a limit film thickness where the lubrication would cease to be hydrodynamic and would be mixed, with asperity contact between surfaces. Further, it is necessary to determine the amount of material taken away after a cycle with wear.

The modification of the ring shape with wear is done by modifying the position of the nodes describing the shape of the discretized ring. The $h_{\text {wear }}$ value specifies the height modification at the nodes where the film thickness becomes smaller than $\lambda \cdot \sigma$. This value is taken as one fourth of the roughness and it is the amount of material worn at the point of minimum film thickness.

When the film thickness becomes lower than the limiting value, the program takes away a specified amount of material from the ring, thus changing the ring shape. This is done by calculating the value of the specific film thickness $\lambda$, see ${ }^{14}$ :

$$
\lambda=\frac{h_{\min }}{\sigma}
$$

Where $h_{\min }$ is the minimum film thickness in the oil distribution and $\sigma$ is the composite surface roughness. This value is given by the square root of the surface roughness the 
liner and the piston ring squared ${ }^{14}$ :

$$
\sigma=\sqrt{R_{q_{\text {liner }}}^{2}+R_{q_{\text {ring }}}^{2}}
$$

In ${ }^{16}$ the value of $\lambda$ which marks the limit between full fluid lubrication and mixed lubrication is at around 4.

\section{Pressure Boundary Conditions for the Ring}

The piston ring seals the combustion chamber, so that a pressure drop across the ring is present. The fully flooded and Reynolds cavitation condition from ${ }^{20}$ were adopted.

A typical pressure distribution for the first compression ring is seen in figure 6 , showing the pressure above $\left(P_{c y l}\right)$ and below $\left(P_{12}\right)$ the ring.

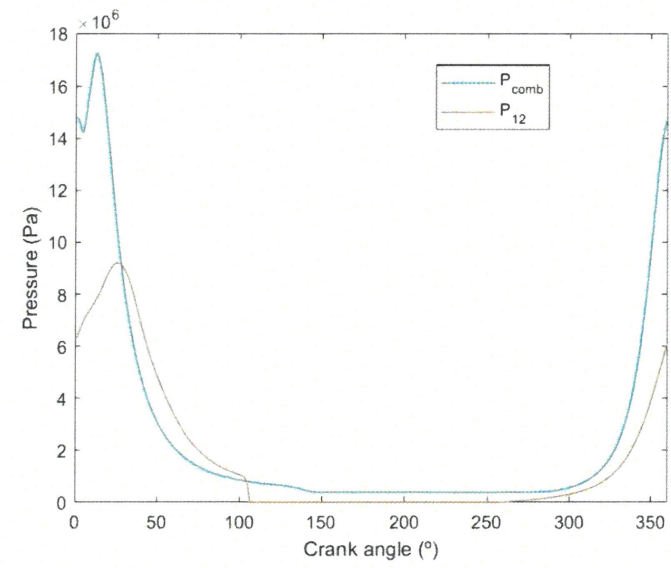

Figure 6. The pressure above and below the top piston ring in a large two stroke diesel engine.

\section{Viscosity-Temperature Dependency}

The cylinder liner temperature is changing along the liner with it's highest value at the top dead center and the lowest value at the scavenging ports, see figure 7 .

In this analysis it is assumed that the piston ring temperature is $T_{\text {ring }}=150^{\circ} \mathrm{C}$ and the lube oil temperature is the mean temperature of the liner and the piston ring.

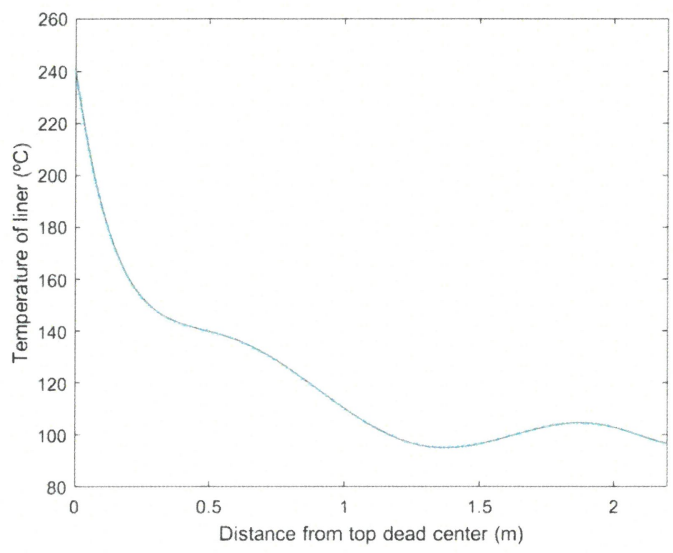

Figure 7. Temperature of the liner dependant on the distance from the top dead center. Simulated data provided by MAN ES.
Ihe lube oil used in the analysis is a SAE50 oil, and the viscosity is assumed to vary according Vogel's equation, ${ }^{19}$ :

$$
\eta=a_{0} \exp \frac{T_{1}}{T_{2}+T_{o i l}}
$$

\section{Ring twist}

The ring deforms due to the forces acting on it. The pressures above and under the ring as a result of the combustion and the movement of the piston causes the ring to twist either downwards, if the pressure above is higher, or upwards when the pressure in the combustion chamber becomes smaller than that between the rings. Also, the ring can be twisted as a result of the twisting moment exerted by the friction force of the ring against the liner.

When it is assumed that the ring does not twist the wear profile will be a truncated parabolic curve, with sharp vertices where the parabola connects with the straight worn surface. This result is unrealistic and causes false pressure peaks. When twisting is considered the final profile will have smoother vertices.

To model this it is assumed that the twisting of the ring is controlled by the bending of the piston land where the ring rests. The deformation is caused by the difference in pressure across the ring and the friction force multiplied by the flexibility of the land.

An approximate bending flexibility $f$ of the piston land is estimated. Using the value of the friction force and the difference in pressures multiplied by the length of the side of the ring the maximum force is calculated.

The friction force equals the integration of the shear stress in the oil film along the ring surface.

Depending of the crank angle the twist from the friction force will have a positive or a negative sign.

In order to simplify matters further it is assumed that the center of rotation is the geometric center of the rings cross section. Two sets of coordinate systems are set up. See figure 8.

First the global system is defined, indicated by the subscript 0 . Its center lies on the liner. The $y_{0}$ axis represents the distance from the liner to the ring and the $x_{0}$ axis is the distance along the ring as shown in figure 8. The local coordinate system, with subscript 1 , is located in the center of rotation and fixed to the center of the ring. This means that in the case of ring twist, this system rotates with the ring.

The two systems are linked together by the twist angle of the ring with respect to it's original position parallel to the liner, and by the distance between the centers of the coordinate systems. A transformation matrix composed by a rotation and a translation links the systems.

$$
\left[\begin{array}{c}
x_{0} \\
y_{0} \\
1
\end{array}\right]=\left[\begin{array}{ccc}
\cos \phi & -\sin \phi & x_{d i f} \\
\sin \phi & \cos \phi & y_{\text {dif }} \\
0 & 0 & 1
\end{array}\right]\left[\begin{array}{c}
x_{1} \\
y_{1} \\
1
\end{array}\right]
$$

From figure 8 we see that the distance between centers in the global y-axis, $y_{\text {dif }}$ is defined as the minimum film thickness $h_{0}$ added to the half width of the ring. Since the ring twist will remain small this is a valid approximation. The difference along the global $\mathrm{x}$-axis is assumed to remain the same during the cycle. 


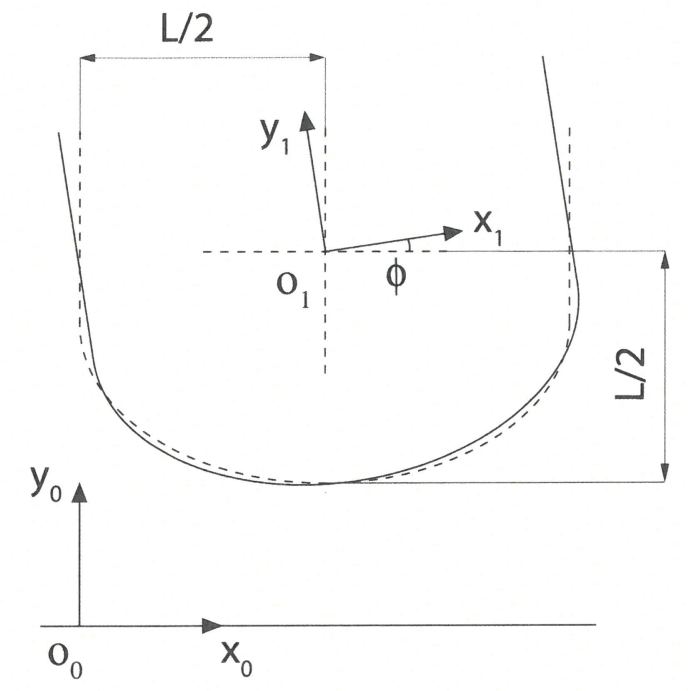

Figure 8. Coordinate systems used to calculate the effect of ring twist on film thickness and calculation of the new difference along $y_{0}$ between coordinate systems.

Ring twist plays an important role with ring wear. Wear occurs when the oil film thickness falls below a minimum value. The location of minimum film thickness $h_{0}$ along the ring width will depend on the twist angle. The ring will not be worn uniformly and parallel to the liner. Furthermore, as the ring is worn the pressure distribution in the oil film will change such that in different cycles the crank angle when the minimum film thickness is reached will change and therefore the plane of wear will change accordingly.

In order to implement the wear pattern at the end of each cycle the ring profile in the global coordinate system is stored and so are the minimum film thicknesses achieved through the cycle.

The crank angle and the ring profile where this minimum occurs is stored. The point $i_{n}$ on the ring where the minimum oil film thickness happened is determined. This point is now raised by an amount of predefined wear, $h_{\text {wear }}$ :

$$
y_{0, \text { in }}=y_{0, \text { in }}+h_{\text {wear }}
$$

In the numerical model the transition between the original profile (parabolic) and the worn profile is non-smooth. This does not correspond to observations from experimental investigations, where the transition is smooth. The numerical model is adjusted to avoid the appearance of non-physical peaks in the pressure distribution by smoothing out sharp edges.

It is important to note that the factors mentioned here are not the only ones which contribute to ring twisting. The ring is subjected to tensions resulting from the temperature gradient along the ring. The highest temperatures are typically found in the interior part of the ring towards the top, where it is nearest to the top of the piston, whilst the coldest part of the ring is that which faces the liner. The temperature gradients results in thermal dilatation. However, this is not included in the current model.

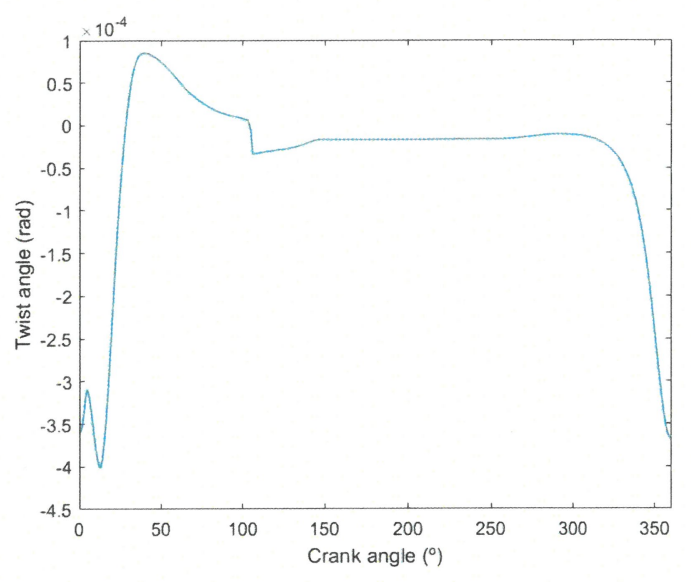

Figure 9. Twist angle through the cycle. Simulation from a finite element model of a piston superimposing the pressures around the piston ring, see figure 6. Data provided by MAN ES.

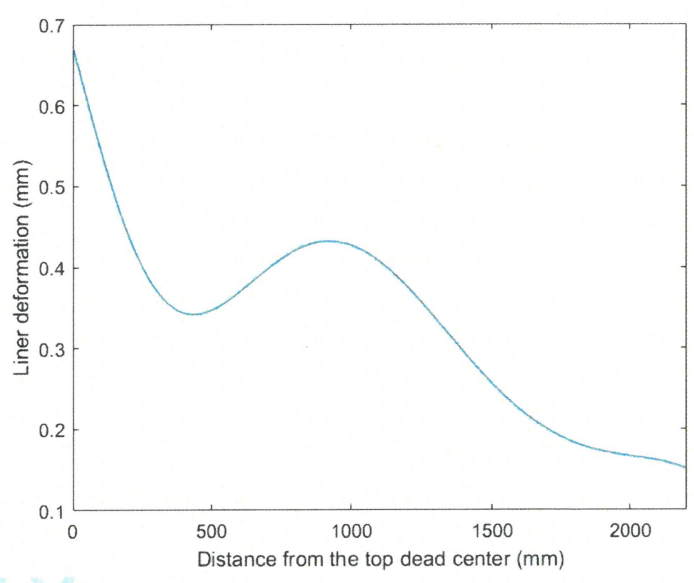

Figure 10. Radial Liner deformation as a function of the distance from the top dead center at $100 \%$ load. Data provided by MAN-ES.

\section{Liner Deformation}

The liner is deformed as a result of the uneven temperature distribution along the liner, see figure 7 and 10, therefore it cannot be considered flat. The thermal distortion means that the piston ring will not be facing a 'flat liner'. The distortion is added by determining the gradient of the deformation of the liner and adding that to the twist angle of the piston ring.

The gradient of the deformation of liner is calculated from the curve shown in figure 10.

\section{Load Variation}

An engine will operate at different load levels according to the operating conditions. Full load, $100 \%$, is rarely reached.

In order to take load variation into account it is necessary to consider which aspects of the operating conditions are affected by the load. As the load changes so do the temperature, the pressure and the speed.

A change in the running condition will affect the temperature of the parts. This temperature influences the viscosity and the deformation of the liner and will in turn change the crank angles at which wear will occur. To 


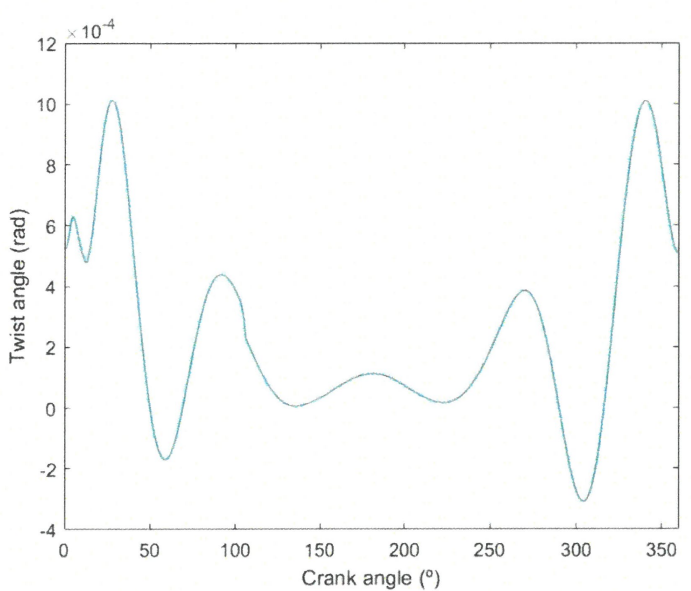

Figure 11. The resulting twist angle, the sum of twist from figure 9 through the cycle with a non-flat liner at $100 \%$ load.

Table 2. Variation of temperature and speed with the load. Data provided by MAN-ES.

\begin{tabular}{|c|c|c|}
\hline Load & $T_{\text {ring }}$ & RPM \\
\hline $100 \%$ & $150^{\circ} \mathrm{C}$ & 123 \\
\hline $50 \%$ & $100^{\circ} \mathrm{C}$ & 98 \\
\hline $25 \%$ & $80^{\circ} \mathrm{C}$ & 78 \\
\hline
\end{tabular}

apply the temperature variation to the liner deformation it is assumed that the relation between the deformation and the temperature is linear. Furthermore a change in the running condition affects the combustion pressure which will have an effect in several aspects. One will be the angle by which the ring will be twisted. The external force exerted on the ring also depends on the maximum pressure and this has a direct impact on the film thickness. Additionally, by changing the pressures on the sides of the ring the boundary conditions for Reynolds equation change and therefore the overall pressure distribution will change.

A load pattern for the piston ring consists of a combination of a percentage of full load, number of cycles and a ring profile modification value. By applying different load patterns different worn profiles will be obtained. Several load patterns were applied, three of these are shown in table 3. These apply the same loads in the same order changing the initial load.

Figure 12 shows the profile of the ring as it is worn over the cycles. When comparing the shape of the ring in this figure to results provided by MAN in figure 14 the wear pattern is similar. In this ring the largest amount of wear has occurred during the first cycles.

The load patterns are listed in figure 13. These three patterns alternate the load in the same order but changing the starting load. It is possible to see that regardless of the initial load the final shape was identical. However, in other tests which ran with different loads in different order the results would vary.

\section{Conclusion}

Piston ring wear is a phenomenon which depends upon many variables and physical aspects. This analysis has attempted to take into account the factors which play a significant role in the development of wear and as a result the developed model
Table 3. Load changes and wear results for three particular load patterns.

\begin{tabular}{|c|lll|lll|}
\cline { 2 - 7 } \multicolumn{1}{c|}{} & \multicolumn{3}{c|}{ Load Pattern } & \multicolumn{3}{c|}{ Cycles with wear } \\
\hline Cycles & $\mathrm{a}$ & $\mathrm{b}$ & $\mathrm{c}$ & $\mathrm{a}$ & $\mathrm{b}$ & $\mathrm{c}$ \\
\hline 100 & 100 & 25 & 50 & 90 & 0 & 22 \\
100 & 25 & 50 & 100 & 3 & 22 & 64 \\
100 & 50 & 100 & 25 & 0 & 64 & 3 \\
100 & 100 & 25 & 50 & 5 & 3 & 0 \\
100 & 25 & 50 & 100 & 1 & 0 & 5 \\
100 & 50 & 100 & 25 & 1 & 5 & 1 \\
100 & 100 & 25 & 50 & 0 & 1 & 1 \\
100 & 25 & 50 & 100 & 1 & 1 & 0 \\
100 & 50 & 100 & 25 & 0 & 0 & 1 \\
100 & 100 & 25 & 50 & 2 & 1 & 0 \\
100 & 25 & 50 & 100 & 0 & 0 & 2 \\
100 & 50 & 100 & 25 & 1 & 2 & 0 \\
100 & 100 & 25 & 50 & 0 & 0 & 0 \\
100 & 25 & 50 & 100 & 0 & 0 & 0 \\
100 & 50 & 100 & 25 & 0 & 0 & 0 \\
\hline
\end{tabular}

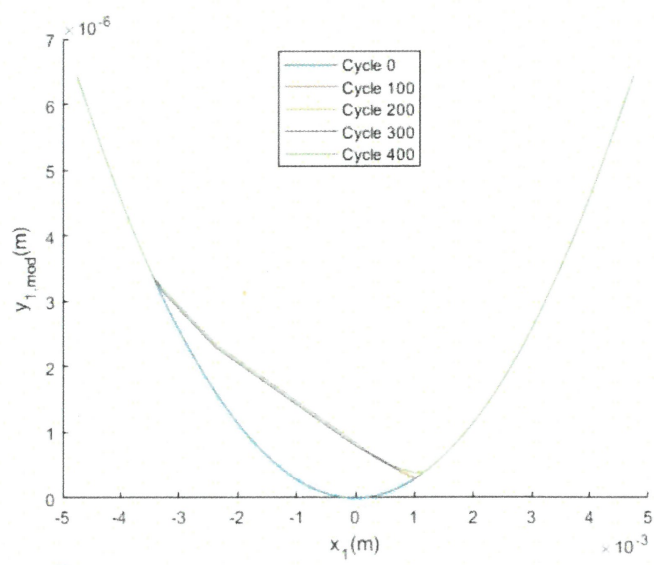

Figure 12. Ring profile after different numbers of cycles following the load pattern a in table 3 . The cycle number refers to the accumulated number of cycles for the ring.

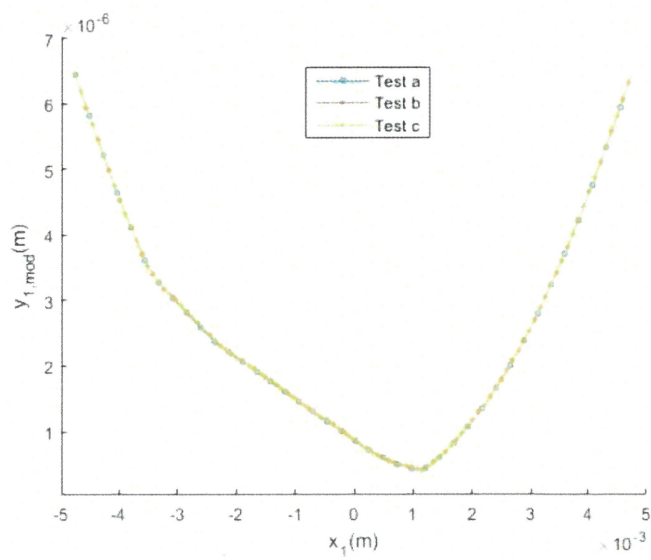

Figure 13. Final worn ring profiles for the three load patterns in table 3 .

is able to predict the final shape of the ring with reasonable accuracy from a qualitative point of view.

One of the key aspects in predicting this final shape was the liner deformation. Applying a 'flat' liner the model 

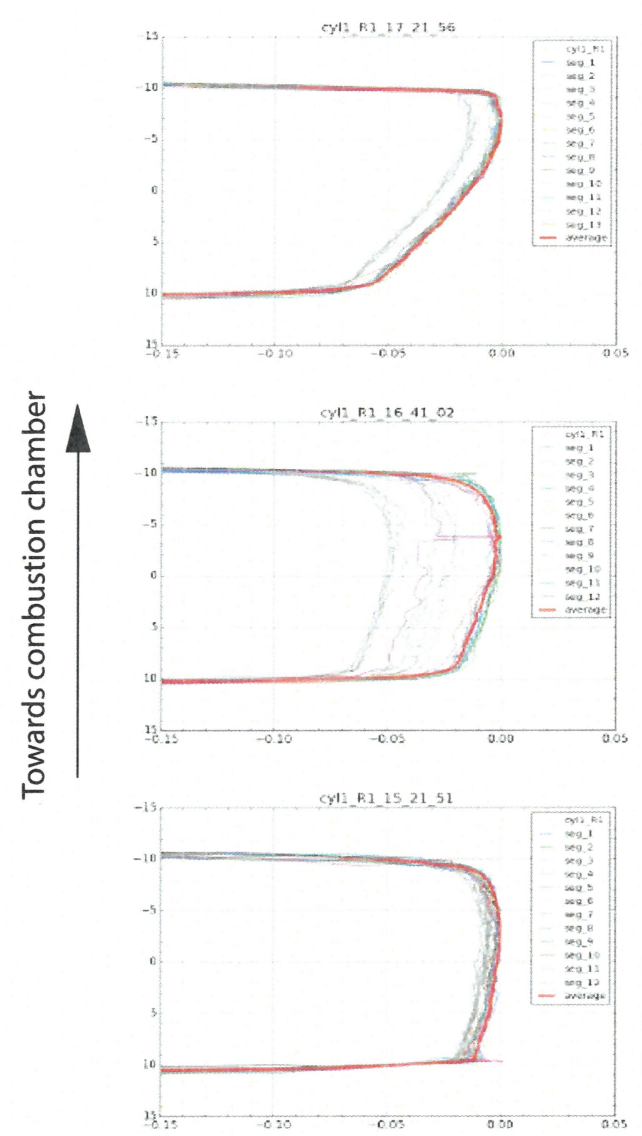

Figure 14. Wear profile for a ring from a large two stroke engine. The lowest image shows an unworn ring, the middle image shows the profile after running for a few thousand hours and the upper image after an additional 1000-2000 hours. Data provided by MAN ES.

predicts wear profiles which do not match those found in real engines. Taking into account the liner deformation deformed the results. Previous to creating the model the role of liner deformation was not expected to be important. Nevertheless, from the results it is interesting to note how it does indeed influence the final profile of the ring.

Another important finding is that the running history of the engine influences the shape of the running surface of the ring. It was found that when running at different loads and with different load patterns the final profiles obtained would be different and that the loads with which the ring had been running previously could determine how the ring would behave in future, as a consequence of the accumulated wear.

It was possible to see how the order in which the loads were applied until wear stop would not change the final result however, if the load history changed, that is which loads were applied, the results would vary.

When modelling the behaviour of the ring some simplifications and assumptions were made. An important simplification which was made at the beginning of the work was to consider the problem as axi-symmetric, which simplified considerably both the solving of the Reynolds equation as well as the programming. This was a reasonable assumption, since only minor variation in the wear is observed at different sections of the ring in the circumferential direction, caused by the opening in the ring which allows it to adapt to the geometry of the liner. This results in that the conditions in the vicinity of the opening will be different to those in the regions further away. In experiments it has been found that the highest wear rates are found in the region furthest away from the opening.

A possible line of future work would be the introduction into the model of other aspects which have been overlooked or deemed unimportant in the present work. An example would be the operation of the engine under starved conditions and how this would have an effect on film thickness and wear. Other considerations would be the thermal dilation of both the piston and the ring as a result of the higher temperatures on the top side of the piston in comparison with the bottom.

Also, an interesting aspect of load variation was also left out, and that is the effect of the transitory period from one load to the other. This means that, for example, when switching from a load of $100 \%$ to $25 \%$ there is a time span during which the temperatures of ring and liner, and therefore oil, are decreasing. The study of how this could affect the distribution of wear could be of use, since in normal operations engines undergo many load changes. This aspect has not been considered.

Overall, this work has taken into account the variables relevant in piston ring wear and eventually yields a solution which is close to the experimental data.

\section{References}

1. Priest M, Dowson D and Taylor CM. Predictive wear modelling of lubricated piston rings in a diesel engine. Wear. 1999;231(1):89-101

2. Morris N, Rahmani R, Rahnejat $\mathrm{H}$ et al. The influence of piston ring geometry and topography on friction. Proceedings of the Institution of Mechanical Engineers, Part J: Journal of Engineering Tribology. 2013; 227(2): 141-153.

3. Coy RC. Practical applications of lubrication models in engines. Tribol. Int. 1998;31(10):563-571.

4. Sherrington I. and Mercer S. The use of topography-based parameters for the assessment and prediction of surface wear. Lubr. Sci. 2000;7(1):1-11.

5. Priest M. and Taylor CM. Automobile engine tribology approaching the surface. Wear. 2000;241(2):193-203.

6. Hu YZ., Li N. and Tnder K. A dynamic model for lubricated sliding wear and running-in. J. Tribol. 1991; 113(3):499-505.

7. Ma Z. et al. Break-in liner wear and piston ring assembly friction in a spark ignited engine. Tribol. Trans. 1998;41(4):497504.

8. Henien NA. In situ wear measuring technique in engine cylinders. Tribol. Trans. 1998;41(4):579-585.

9. Castleman RA. A hydrodynamical Theory of Piston Ring Lubrication. Physics. 1936;7:364-367.

10. Papadopoulos P., Priest M. and Rainforth WM. Investigation of fundamental wear mechanisms at the piston ring and cylinder wall interface in internal combustion engines. P. I. Mech. Eng. J.-J. Eng. 2007;221:333-343.

11. Truhana JJ., Qu J. and Blau PJ. A rig test to measure friction and wear of heavy duty diesel engine piston rings and cylinder liners using realistic lubricants. Tribol. Int. 2005;38(3):211218. 
12. Ma Z., Henien NA. and Bryzik W. A Model for Wear and Friction in Cylinder Liners and Piston Rings. Tribol. Trans. 2006;49(3):315-327.

13. Zhang J.et al. 3-D Numerical Simulation and Experiment Study on the Wear of Piston Ring-Cylinder Liner. Adv. Mater. Res. 2010;139-141:1036-1039.

14. Bernard J. Hamrock BJ. Fundamentals of Fluid Film Lubrication. Marcel Dekker, 1994.

15. Lund JW. Self-Excited, Stationary Whirl Orbits of a Journal in a Sleeve Bearing. PhD Thesis, Rensselaer Polytechnic Institute, New York, USA, 1966.

16. Lund JW. Review of the Concept of Dynamic Coefficients for Fluid Film Bearings. J. Tribol.-T. ASME. 1987;109(1):37-41.

17. Klit P and Vølund A. Shaft Center orbit in Dynamically Loaded Radial Bearings. In: World Tribology Congress III, September 2005.

18. Vølund A. Measurement and Calculation of Frictional Loss in Large Two-Stroke Engines. PhD Thesis, Technical University of Denmark, Dept. of Mechanical Engineering, Copenhagen, Denmark 2003.

19. Harigaya Y, Suzuki M, Toda F et al. Analysis of oil film thickness and heat transfer on a piston ring of a diesel engine: effect of lubricant viscosity. J. Eng. Gas Turbines Power. 2006;128(3):685-693.

20. Han DC. and Lee JS. Analysis of the Piston Ring Lubrication with a New Boundary Condition. Tribol. Int. 1998;31(12):753760 